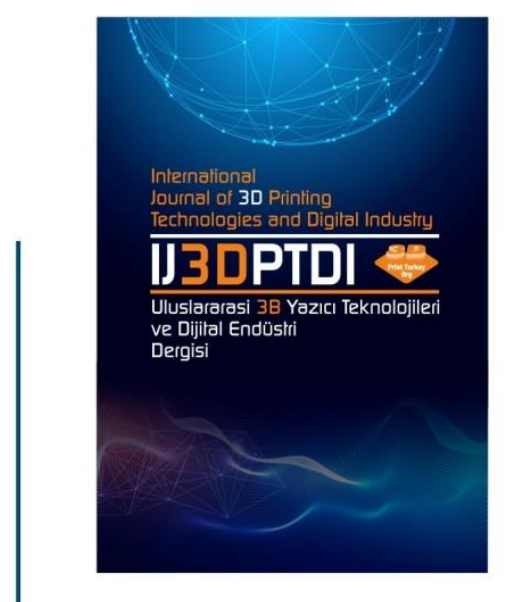

ULUSLARARASI 3B YAZICI TEKNOLOJILERI

VE DIJITAL ENDÜSTRI DERGISI

INTERNATIONAL JOURNAL QF 3D PRINTING TECHNQLOGIES AND DIGITAL INDUSTRY

I55N:2602-3350 [Online]

URL: https://dergipark.org.tr/ij3dptdi

\begin{abstract}
ANALYTICAL AND NUMERICAL INVESTIGATION OF ELASTIC STRESSES IN THERMOPLASTIC MATRIX COMPOSITE DISCS UNDER TEMPERATURE EFFECT
\end{abstract}

Yazarlar (Authors): Hüseyin Fırat Kayıran (D) *

Bu makaleye şu şekilde atıfta bulunabilirsiniz (To cite to this article): Kayıran H.F. "Analytical And Numerical Investigation Of Elastic Stresses In Thermoplastic Matrix Composite Discs Under Temperature Effect" Int. J. of 3D Printing Tech. Dig. Ind., 5(3): 730-741, (2021). 


\title{
ANALYTICALAND NUMERICAL INVESTIGATION OF ELASTIC STRESSES IN THERMOPLASTIC MATRIX COMPOSITE DISCS UNDER TEMPERATURE EFFECT
}

\author{
Hüseyin Fırat Kayıran ${ }^{a}$ (D)* \\ ${ }^{a}$ Tarım ve Kırsal Kalkınmayı Destekleme Kurumu (TKDK), Mersin İl Koordinatörlüğü, TURKEY. \\ *Correponding Author: huseyinfirat.kayiran@tkdk.gov.tr
}

(Received: 04.11.2021; Revised: 14.12.2021; Accepted: 29.12.2021)

\begin{abstract}
In this study, elastic stress analysis was performed on thermoplastic composite discs. The modulus of elasticity of thermoplastic composite discs is also different from each other. Our goal is to study elastic stretching. The field of application of primitive stresses caused by uneven temperature distribution in engineering is quite large. Under the parabolic temperature distribution of the disks, radial stresses formed on the inner and outer parts of the disks were calculated by assuming that the modulus of elasticity does not change with temperature at temperatures of $30^{\circ} \mathrm{C}, 60^{\circ} \mathrm{C}, 90^{\circ} \mathrm{C}, 120^{\circ} \mathrm{C}$ on the inner and outer surfaces of the disk. During the study, analytical and numerical analysis was performed using a computer program and mathematically modeled ANSYS programs.

Both methods give similar results. In other words, the differences analytical and numerical results can be ignored. At the end of this study, it was determined that the radial and tangential stress values were higher at high temperatures than at low temperatures. It has been established that tangential stresses are much larger than radial stresses. The purpose of this article is to study the behavior of the thermal load on two different thermoplastic disks.
\end{abstract}

Keywords: Thermoplastic disc, Elastic stress analysis, Modulus of elasticity, Thermoplastic composite, Parabolic temperature distribution

\section{INTRODUCTION}

Discs are used in many of the machine parts. Composite materials, on the other hand, are frequently used in the fields of automotive industry, aircraft industry, space industry, defense industry, food industry, textile industry. It is of great importance to know in advance the properties we want according to the area where the materials exposed to temperature will be used. When the literature is examined, it has been seen that thermal stress analyzes are made on metal discs. It has been observed that the studies conducted on thermal stress analysis on thermoplastic discs are not sufficient. Thermoplastic composites are widely used in aviation. In particular, carbon fiber reinforced thermoplastic composites have started to be used as structural materials for both high performance aerospace applications and other industrial applications. High deformation resistance, superior fracture toughness and impact resistance; Short production cycle, unlimited life, recyclability and repairability are some of the features that increase the popularity of these materials [1]. When the thermal stress analyses occurring in disks with aluminum (Al2024-T3), Boron carbide $\left(B^{4} C\right)$ materials were examined, the radial and tangential stresses formed in the disks were determined numerically [2]. He determined the thermal stresses occurring in a bimaterial disk numerically and shared his findings with the literature using graphs [3].

Elastic stress analysis of orthotropic functionally graded discs was performed [4].The thermal stress analysis of cross-reinforced square-hole thermoplastic composite plates was studied. In their study, they shared the results obtained at constant temperature on a square hole reinforced with steel fibers using the method of composite plates with a layer in the middle and finite elements with a thermal load [5]. They calculated residual stresses in thermoplastic materials in their study [6]. In a different study, plastic stresses occurring in composite plates with thermoplastic layers with elliptical holes were investigated. 
Vertical heat loading in the form of weaving was applied to orthotropic layered plates made of steel fiber reinforced composite. Using the finite element method, it was concluded that the stress components occurring in the layers of the material are lower than those on the lower and upper surfaces, and there is an increase in the plastic stress components depending on the number of iterations [7].The behavior of composite materials against high temperatures is different from each other. In different studies, the mechanical properties and thermal behavior of different composite materials were investigated [8-12].

It is vital to investigate the stresses occurring in the discs. Disks are parts of spacecraft and are used quite often when assembling on airplanes. The radial stress and tangential stresses that occur when the materials that make up the disks are changed are radically different from each other [13-16].The parameters taken into account when determining the materials that make up the disks are very important. For example, when choosing composite materials, radiation shielding parameters of different materials and composite material should be taken into account by considering radiation parameters [17-18].

He investigated the elasto-plastic stresses occurring in an aluminum composite plate with an antisymmetric sequence angle with a metal matrix at constant temperature [19]. They analyzed the elastic stresses occurring in disks rated with a simple force function of axially symmetric rotating, functionally graded parabolic and hyperbolic disk profiles [20]. The thermal stresses of laminated composite plates have been studied using the exponential shear deformation theory [21]. By developing Navier solutions for the composite plate in question, they shared the numerical results obtained with the threedimensional flexibility solution available in the literature. In this study, the stresses of thermoplastic composite disks modeled with two different mechanical properties were calculated by assuming that the modulus of elasticity of the material does not change depending on the temperature.

\section{MATERIAL AND METHODS}

In this study, stresses occurring at $30^{\circ} \mathrm{C}, 60{ }^{\circ} \mathrm{C}, 90^{\circ} \mathrm{C}$ and $120^{\circ} \mathrm{C}$ were determined. The inner radius of the thermoplastic matrix composite disk is $40 \mathrm{~mm}$, and the outer radius is $80 \mathrm{~mm}$. For the plane stress state, assuming the disk thickness as a unit, it is taken $\sigma_{\mathrm{Z}}=0$, and the general equilibrium equation for a thin composite disk is as follows [22].It is given in the format. In equation (1), $\mathrm{r}$ is the radius of the disk at any point, $\sigma \mathrm{r}$ is the radial stress, and $\sigma_{\theta}$ is the tangential stress. The modeled disk subjected to thermal stress analysis is given in Figure 1 below.

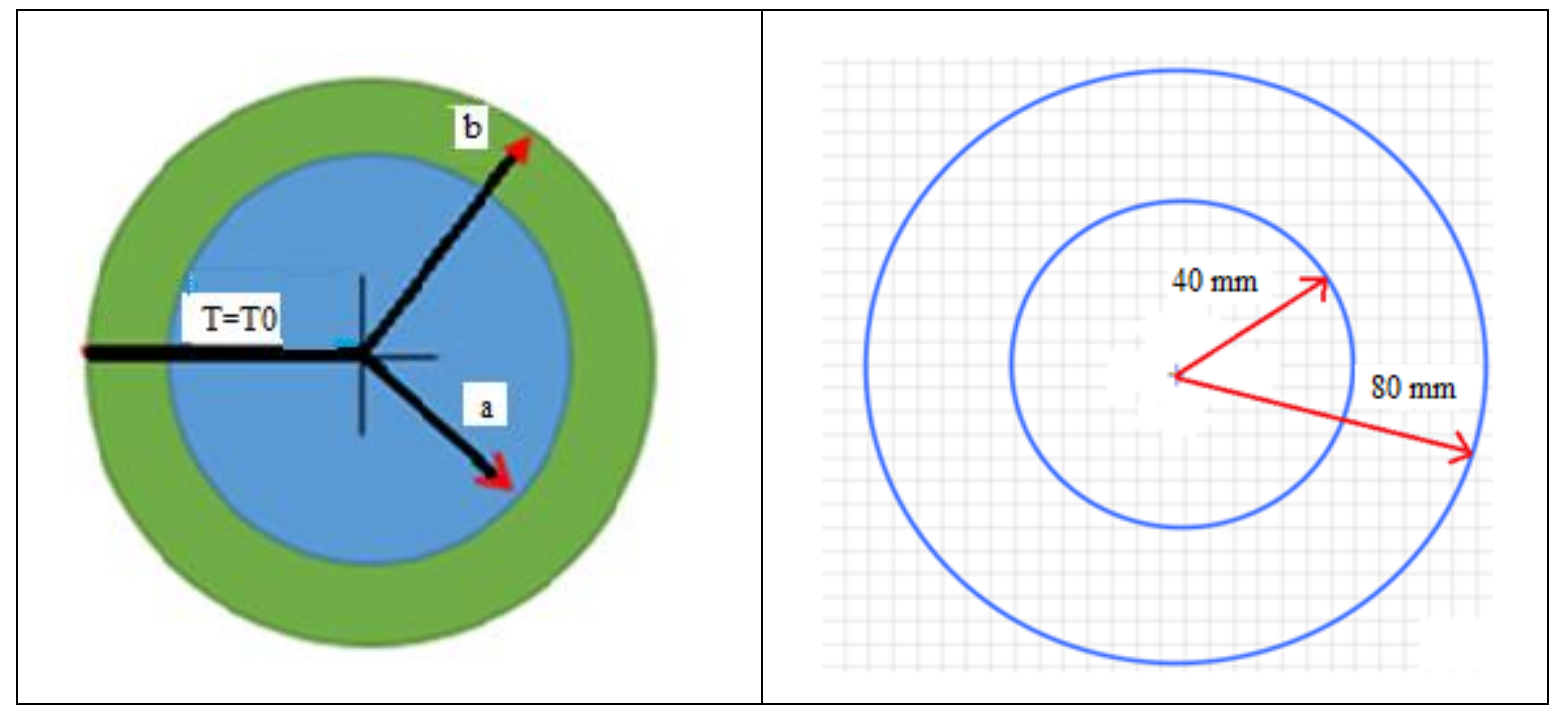

Figure 1. A disk subjected to thermal stress analysis.

$$
\begin{aligned}
& \frac{\mathrm{r}\left(\mathrm{d} \sigma_{\mathrm{r}}\right)}{\mathrm{dr}}+\left(\sigma_{\mathrm{r}}\right)-\left(\sigma_{\theta}\right)=0 \\
& \varepsilon_{\mathrm{r}}=\frac{\mathrm{du}}{\mathrm{dr}}=\mathrm{a}_{\mathrm{rr}} \sigma_{\mathrm{r}}+\mathrm{a}_{\mathrm{r} \theta} \sigma_{\theta}
\end{aligned}
$$




$$
\varepsilon_{\theta}=\frac{\mathrm{u}}{\mathrm{r}}=\mathrm{a}_{\mathrm{r} \theta} \sigma_{\mathrm{r}}+\mathrm{a}_{\theta \theta} \sigma_{\theta}
$$

Where $u$ is the displacement in the radial direction. $\varepsilon_{\mathrm{r}}$ refers to the radial deformation, $\varepsilon_{\theta}$ refers to the tangential deformation. Strain-stress relation [12];

$$
\begin{gathered}
\varepsilon_{\mathrm{r}}=\varepsilon_{\theta}+\mathrm{r} \frac{d \varepsilon_{\theta}}{\mathrm{dr}} \\
\sigma_{\mathrm{r}}=\frac{\mathrm{F}}{\mathrm{r}} \\
\sigma_{\theta}=\frac{\mathrm{dF}}{\mathrm{dr}}
\end{gathered}
$$

in the form. If equations (6) and (7) are applied in equations (4) and (5); obtained. The fitness equation for elongation; It is obtained as. The equilibrium equation where the stress function can be defined as $\mathrm{F}$ and the equations between (1-7) are used to obtain the general equation (11).

$$
a_{\theta \theta} r^{2} \frac{d^{2} F}{d r^{2}}+a_{\theta \theta} r \frac{d F}{d r}-a_{r r} F=-\alpha_{\theta} r^{2} \frac{d T}{d r}+\alpha_{r} \operatorname{Tr}-\alpha_{\theta} \operatorname{Tr}
$$

$\mathrm{T}_{0}$ indicates the first temperature value, $\operatorname{Tr}$ 'indicates the temperature value of any point in the radial direction. For parabolic increasing temperature distribution;

$$
\mathrm{T}=\frac{\mathrm{T}_{0}}{\mathrm{a}^{2}-\mathrm{b}^{2}}\left(\mathrm{a}^{2}-\mathrm{r}^{2}\right)
$$

It happens in the form. The inner radius of the disc $a, b$ is the outer radius of the disc. The function $f$ from the solution of equations;

The stress components are;

$$
\mathrm{F}=\mathrm{C}_{1} \mathrm{r}^{\mathrm{k}}+\mathrm{C}_{2} \mathrm{r}^{-\mathrm{k}-1}+\mathrm{Ar}^{2}+\mathrm{C}
$$

$$
\begin{aligned}
& \sigma_{\mathrm{r}}=\frac{\mathrm{F}}{\mathrm{r}}=\mathrm{C}_{1} \mathrm{r}^{\mathrm{k}-1}+\mathrm{C}_{2} \mathrm{r}^{-\mathrm{k}-1}+\mathrm{Ar}^{2}+\mathrm{C} \\
& \sigma_{\theta}=\frac{\mathrm{dF}}{\mathrm{dr}}=\mathrm{kC}_{1} \mathrm{r}^{\mathrm{k}-1}+\mathrm{kC}_{2} \mathrm{r}^{-\mathrm{k}-1}+3 \mathrm{Ar}^{2}+\mathrm{C}
\end{aligned}
$$

The calculations of $\mathrm{A}$ and $\mathrm{C}, "$"and $\mathrm{k}$ coefficients are as follows.

$$
\begin{aligned}
& A=-\lambda \frac{3\left(\alpha_{\theta}-\alpha_{r}\right)}{a_{\theta \theta}\left(9-k^{2}\right)} \\
& C=\lambda \frac{\left(\alpha_{r}-\alpha_{\theta}\right) b^{2}}{a_{\theta \theta}\left(1-k^{2}\right)} \\
& \lambda=\frac{T_{0}}{\left(b^{2}-a^{2}\right)} \\
& k^{2}=\frac{a_{r r}}{a_{\theta \theta}}
\end{aligned}
$$

For the calculation of integration constants according to $\mathrm{C}_{1}$ and $\mathrm{C}_{2}$ boundary conditions; 


$$
\begin{aligned}
& \mathrm{C}_{1}=\frac{\mathrm{Aa}^{\mathrm{k}+3}+\mathrm{Ca}^{\mathrm{k}+1}-\mathrm{Ab}^{\mathrm{k}+3}-\mathrm{Cb}^{\mathrm{k}+1}}{\left(\mathrm{~b}^{2 \mathrm{k}}-\mathrm{a}^{2 \mathrm{k}}\right)} \\
& \mathrm{C}_{2}=-\mathrm{C}_{1} \mathrm{a}^{2 \mathrm{k}}-\mathrm{Aa}^{\mathrm{k}+3}-\mathrm{Ca}^{\mathrm{k}+1}
\end{aligned}
$$

\section{EXPERIMENTAL RESULTS}

In this study, thermal stresses occurring under parabolic increasing temperature distributions were investigated in two different disks modeled with composite thermoplastic material. The disks are fixed and their dimensions are modeled as $\mathrm{a}=40 \mathrm{~mm}, \mathrm{c}=80 \mathrm{~mm}$. The solutions were obtained using $30^{\circ} \mathrm{C}$, $60^{\circ} \mathrm{C}$, and $90^{\circ} \mathrm{C}$ temperature values. It was assumed that the modulus of elasticity does not undergo any changes with temperature. Previous studies in the literature have been investigated for the material properties of thermoplastic composite discs [23-24]. In particular, many analyses can be easily performed using the finite element method. The ANSYS program is also a package program that can perform various analyzes based on the finite element method. With this study, a mathematical model has been developed with a computer program to calculate the stresses occurring at different temperatures. The finite element method is a preferred method for solving many engineering problems in different fields. The finite element method has been preferred for the solution. For this purpose, ANSYS software was used for modeling and analysis.

In a similar study, the mechanical (Disc-I) properties of the thermoplastic composite material produced were used. The materials consist of low density polyethylene as a thermoplastic matrix and steel fibers as a curve. In general, in the production of materials; after the raw polyethylene granules are placed in a mold heated by an electric resistor, a polyethylene layer with a thickness of $1 \mathrm{~mm}$ is produced for the preparation of polyethylene layers. Another thermoplastic material (Disc-II) is high density polyethylene (HDPE) reinforced with steel wires produced at Dokuz Eylül University mechanical Laboratory. The properties of the thermoplastic composite materials determined in this study are given in Table 1.

Table 1. Mechanical properties of Thermoplastic Disc-I [5]-[25].

\begin{tabular}{cccc}
\hline Properties & Unit & Disc-I & Disc-II \\
\hline $\mathbf{E}_{\ominus}$ & $\mathbf{G P a}$ & 11.3 & 41 \\
\hline $\mathbf{E}_{\mathbf{r}}$ & $\mathbf{G P a}$ & 2.6 & 1.2 \\
\hline $\mathbf{k}$ & $\mathbf{1 / 1}$ & 6.59 & 5.84 \\
\hline $\boldsymbol{\alpha}_{\mathbf{r}}$ & $\mathbf{1 /}\left({ }^{\circ} \mathbf{C}\right)$ & $130 \times 10^{-6}$ & $131 \times 10^{-6}$ \\
\hline $\boldsymbol{\alpha}_{\ominus}$ & $\mathbf{1 /}\left({ }^{\circ} \mathbf{C}\right)$ & $12.8 \times 10^{-6}$ & $13.1 \times 10^{-6}$ \\
\hline
\end{tabular}

Table 2 shows the tangential stresses that occur in Thermoplastic discs.

Table 2. Tangential elastic stresses in discs.

\begin{tabular}{ccccc}
\hline & $\mathbf{3 0}^{\circ} \mathbf{C}$ & $\mathbf{6 0}^{\circ} \mathbf{C}$ & $\mathbf{9 0}^{\circ} \mathbf{C}$ & $\mathbf{1 2 0}^{\circ} \mathbf{C}$ \\
\hline Material Radius & 7.19 & 14.39 & 21.59 & 28.79 \\
\hline $\begin{array}{c}\text { Disc-I } \\
\text { Inner }\end{array}$ & 30.87 & 61.74 & 92.61 & 123.49 \\
\hline $\begin{array}{c}\text { Disc-II } \\
\text { Inner }\end{array}$ & -3.67 & -7.34 & -11.01 & -14.69 \\
\hline $\begin{array}{c}\text { Disc-I } \\
\text { Inner }\end{array}$ & -15.60 & -31.21 & -46.82 & -62.42 \\
\hline $\begin{array}{c}\text { Disc-II } \\
\text { Inner }\end{array}$ & 7.19 & 14.39 & 21.59 & 28.79 \\
\hline
\end{tabular}

Table 3 shows the radial stresses that occur in Thermoplastic discs. 
Table 3. Radial elastic stresses in discs.

\begin{tabular}{ccccc}
\hline & $\mathbf{3 0}^{\circ} \mathbf{C}$ & $\mathbf{6 0}^{\circ} \mathbf{C}$ & $\mathbf{9 0}^{\circ} \mathbf{C}$ & $\mathbf{1 2 0}^{\circ} \mathbf{C}$ \\
\hline Material Radius & 0 & 0 & 0 & 0 \\
\hline $\begin{array}{c}\text { Disc-I } \\
\text { Inner }\end{array}$ & 0 & 0 & 0 & 0 \\
\hline $\begin{array}{c}\text { Disc-II } \\
\text { Inner }\end{array}$ & 0 & 0 & 0 & 0 \\
\hline $\begin{array}{c}\text { Disc-I } \\
\text { Inner }\end{array}$ & 0 & 0 & 0 & 0 \\
\hline $\begin{array}{c}\text { Disc-II } \\
\text { Inner }\end{array}$ & 0 & 0 & 0 & 0 \\
\hline
\end{tabular}

In Table 2 and Table 3, the elastic tangential stresses obtained for Disk-I and Disk-II modeled from thermoplastic composite materials are given. Tensile stress occurs on the inner parts of the disc and compression stress occurs on the outer parts. Figure 2 shows the disk modeled in ANSYS program.

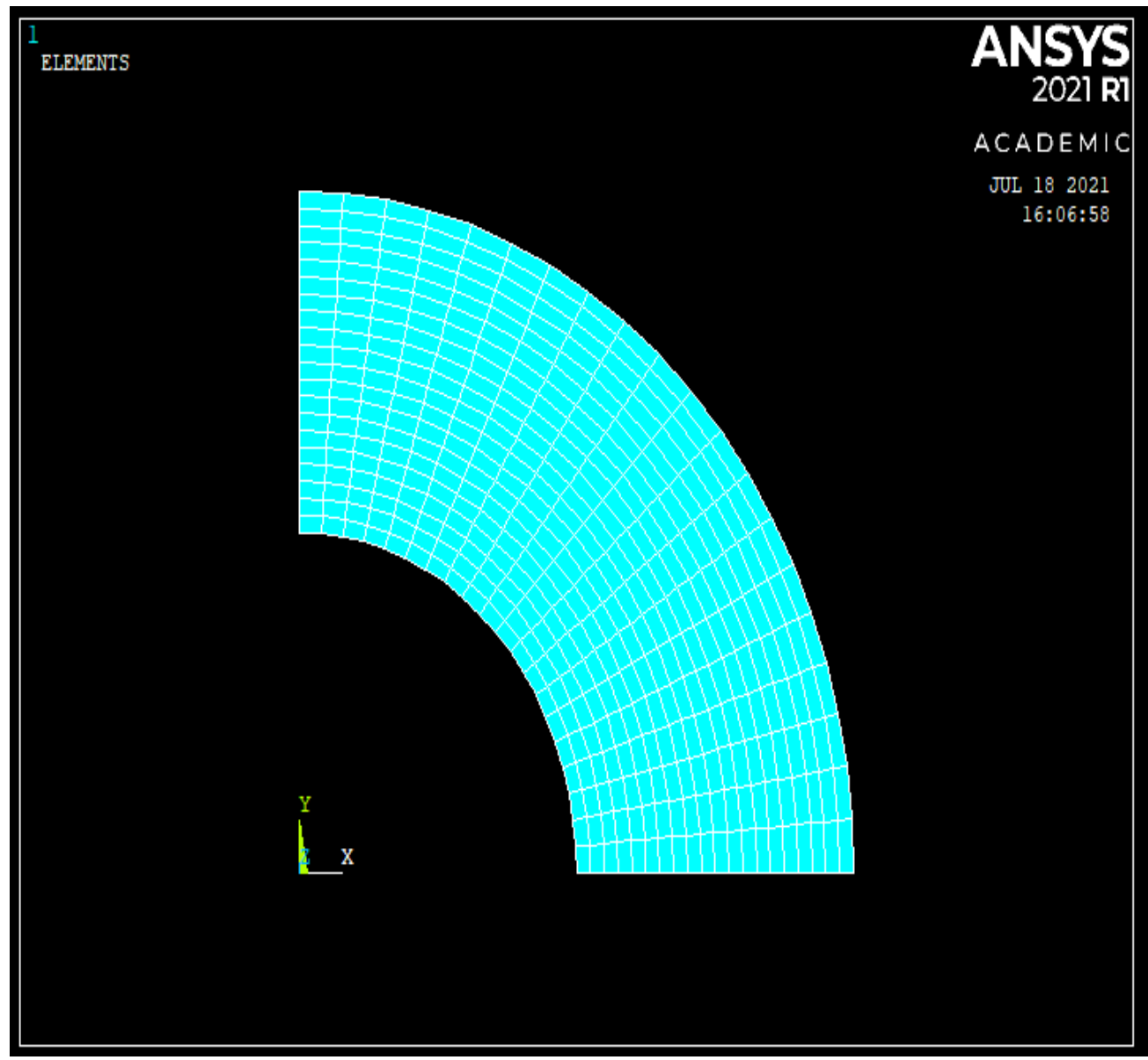

Figure 2. Disc modeled on ANSYS program.

The radial stresses formed on the disks are zero on the innermost and outermost surfaces. Figure 3 shows the radial elastic stress occurring in Disk-I. 


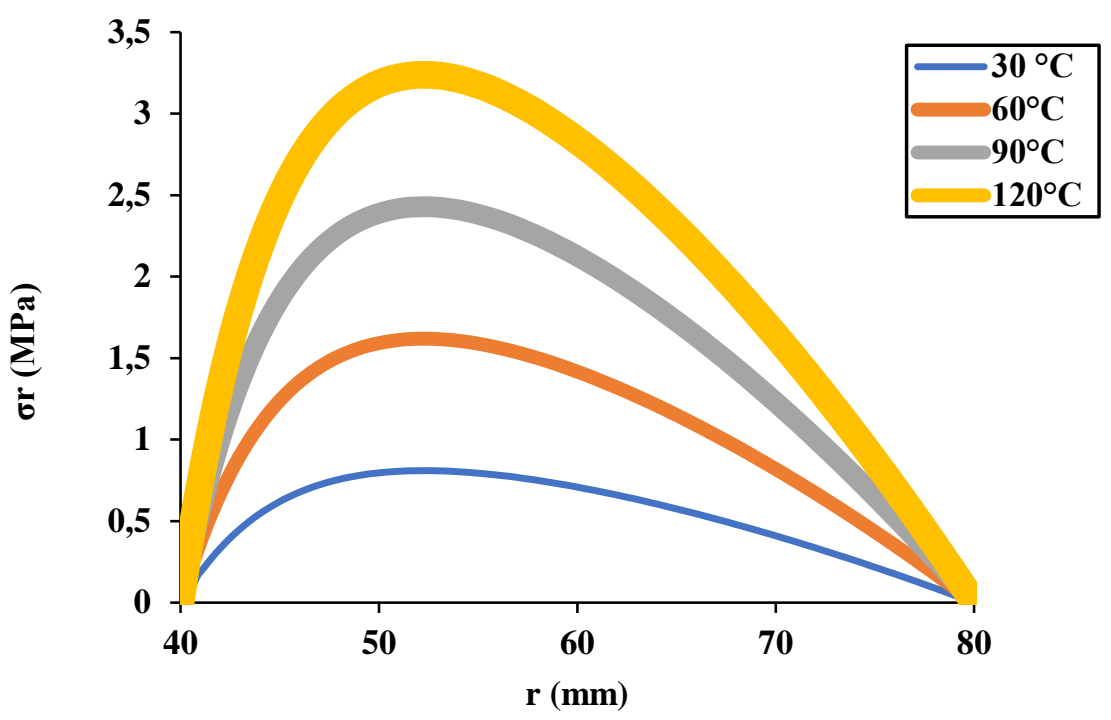

Figure 3. Radial elastic stress occurring in Disc-I.

As can be seen in figure 4 below, the tangential stresses that occur in the innermost and outermost regions of the disk are zero. It is observed that radial stresses occur as a tensile stress in the entire region of the disk. The radial stress values increase from the inner surface of the disk to the region of $\mathrm{r}=52 \mathrm{~mm}$, while they decrease from this point to the outer regions. Figure 4 shows the tangential elastic stress occurring in Disk-I.

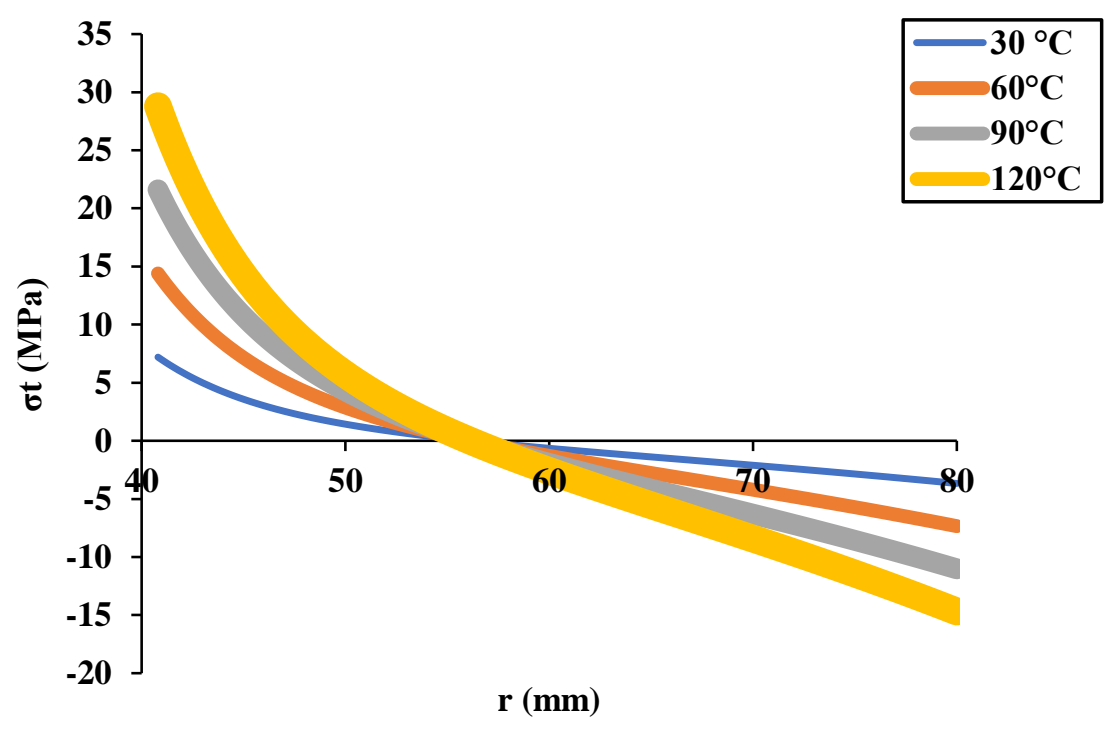

Figure 4. Tangential elastic stress occurring in Disc-I.

As the temperature value increases, the tensile values of the disks also increase. The stress acts as a tensile stress towards the inner region of the disk. It acts as a pressing stress towards the outer region of the disk. The tangential stresses that occur in the inner region of the disk are greater than the tangential stresses that occur in the outer region of the disk. As the temperature value increases, the tangential stress values increase proportionally. The tangential stress value is $7.199 \mathrm{MPa}$ on the inner surface of the disk for a temperature of $30^{\circ} \mathrm{C}$. For a temperature of $60^{\circ} \mathrm{C}$, it is $14.398 \mathrm{MPa}$. The tangential stress that occurs on the innermost surface of the disk for a temperature of $120{ }^{\circ} \mathrm{C}$ is 28.796 MPa. In Figure 5, the radial stresses occurring in Disc-II are shown as graphs. 


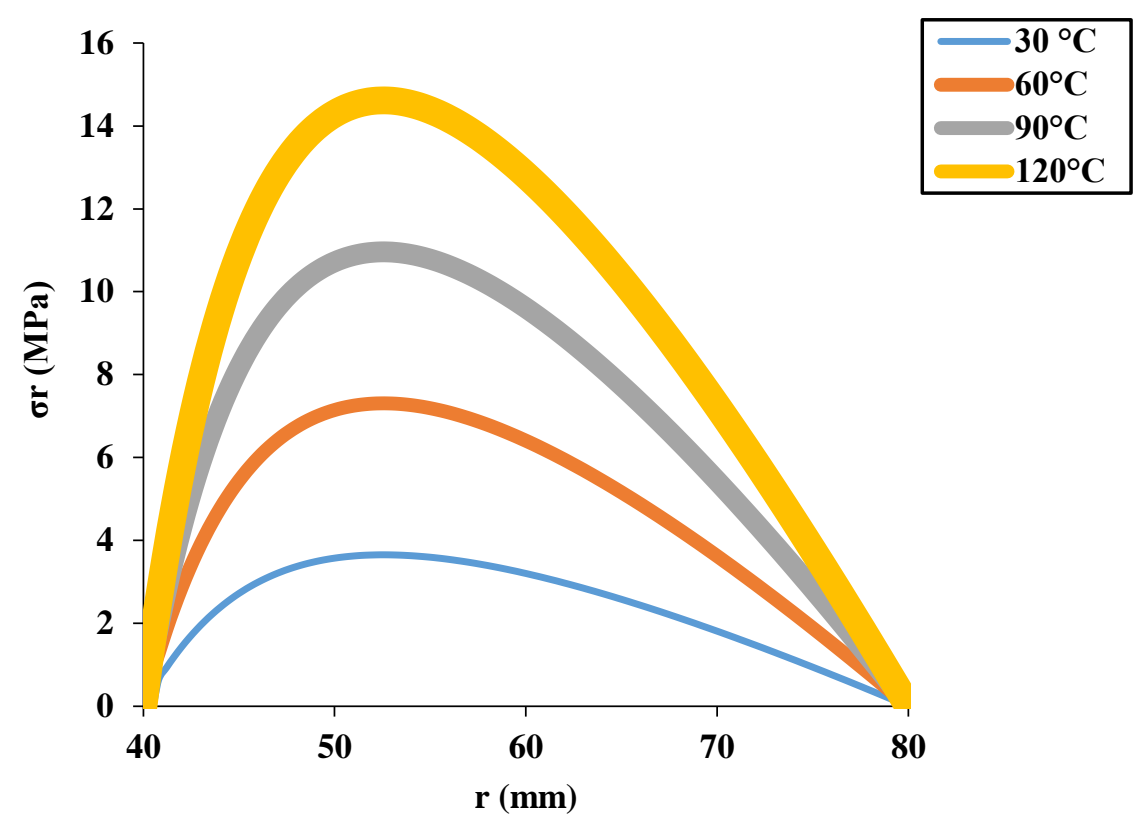

Figure 5. Radial elastic stress occurring in Disc-II.

In Figure 5, radial stresses are determined as tensile stresses in the entire region of the disk. For each temperature value, the intensity of the radial stress increases in the inner region of the disk up to the region of $r=52 \mathrm{~mm}$. It is observed that as the temperature increases after the $52.4 \mathrm{~mm}$ region of the disk, the stress also increases. The radial stress value occurring in the $\mathrm{R}=42 \mathrm{~mm}$ region is $1.432 \mathrm{MPa}$ for a temperature of $30^{\circ} \mathrm{C}$, it is determined as $5.729 \mathrm{MPa}$ for a temperature of $120{ }^{\circ} \mathrm{C}$. Figure 6 shows the tangential stresses occurring in Disc-II.

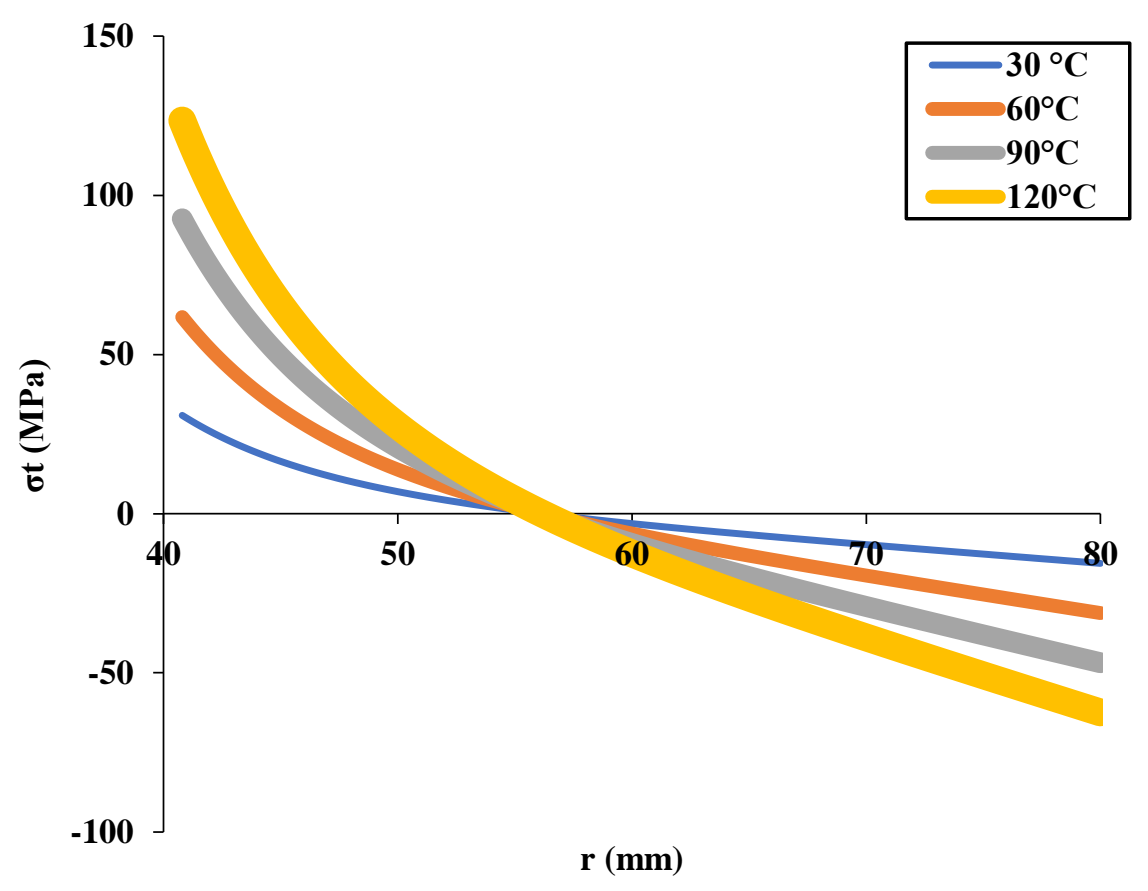

Figure 6. Tangential elastic stress occurring in Disc-II. 
As shown in Figure 5; tangential stresses are determined as tensile stresses in the inner region of the disk. It were obtained as a pressing stress in the outer region of the disk. It is observed that as the temperature increases, the tangential stress values also increase proportionally.

The tangential stress value was determined as $-30.872 \mathrm{MPa}$ on the inner surface of the disk at a temperature of $30{ }^{\circ} \mathrm{C}$. For a temperature of $60{ }^{\circ} \mathrm{C}$, it is $-61.745 \mathrm{MPa}$. For a temperature of $120{ }^{\circ} \mathrm{C}$, the tangential stress that occurs on the innermost surface of the disk is -123.49 MPa.The tangential stress that occurs on the innermost surface of the disks are given in Figure 7.

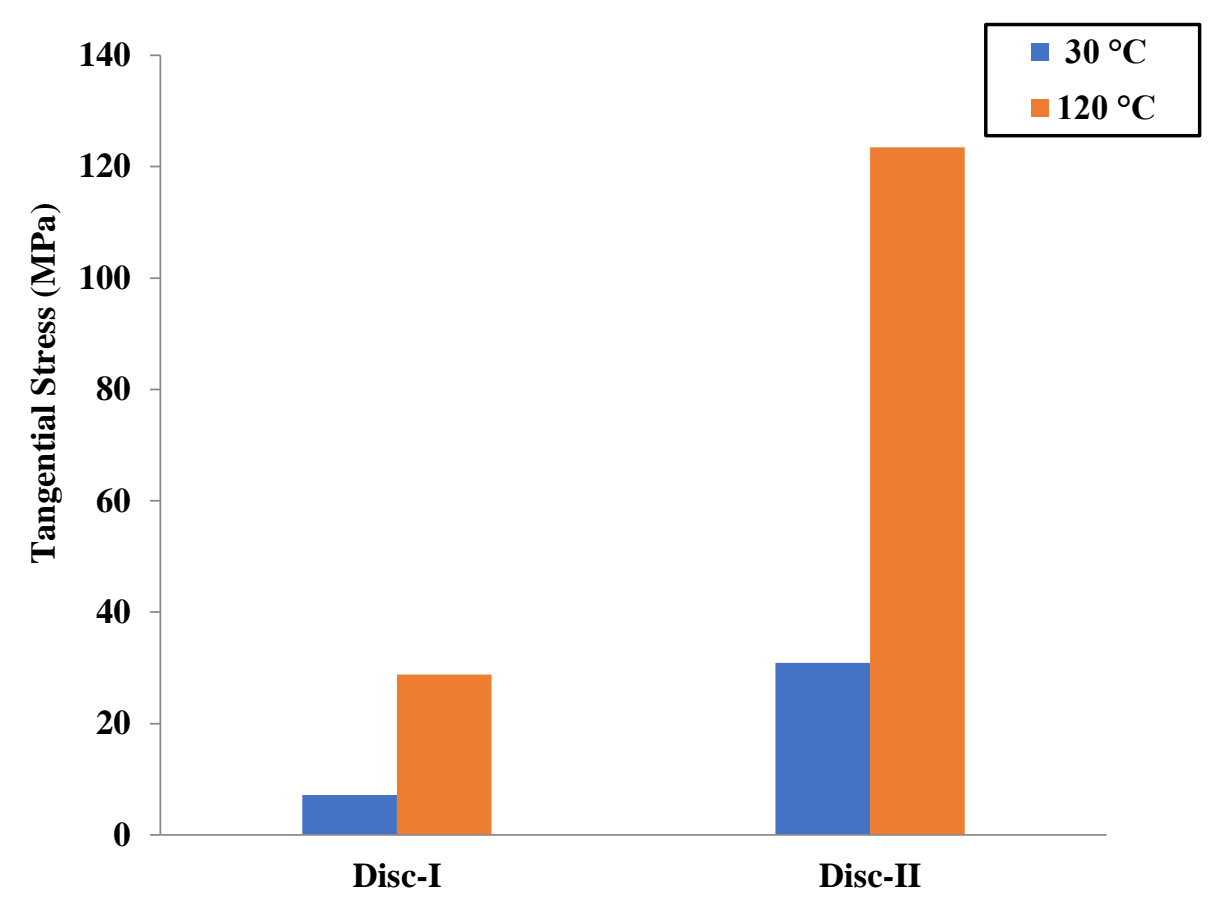

Figure 7. The tangential stress that occurs on the innermost surface of the disk.

The tangential stress that occurs on the outer part of the disks are given in Figure 8.

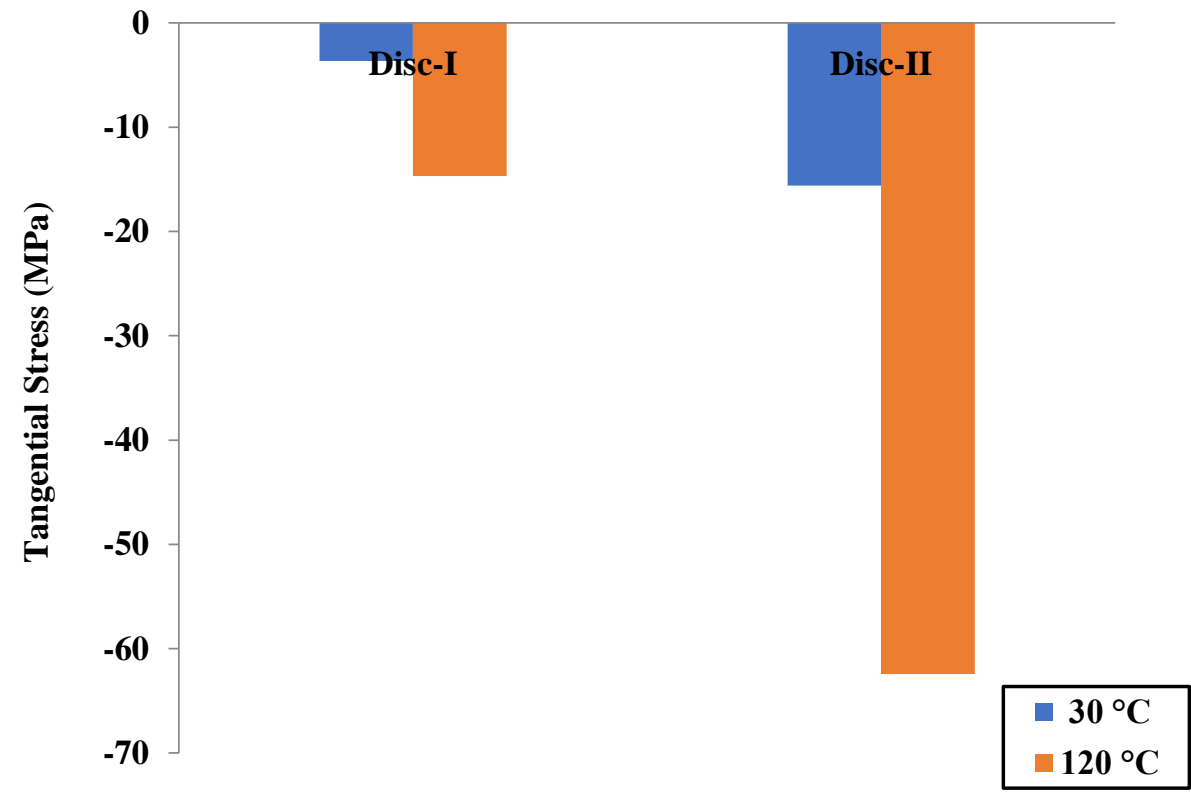

Figure 8. The tangential stress that occurs on the outer part of the disks. 
Figure 9 shows the stresses obtained from the ANSYS program for Disc-I.

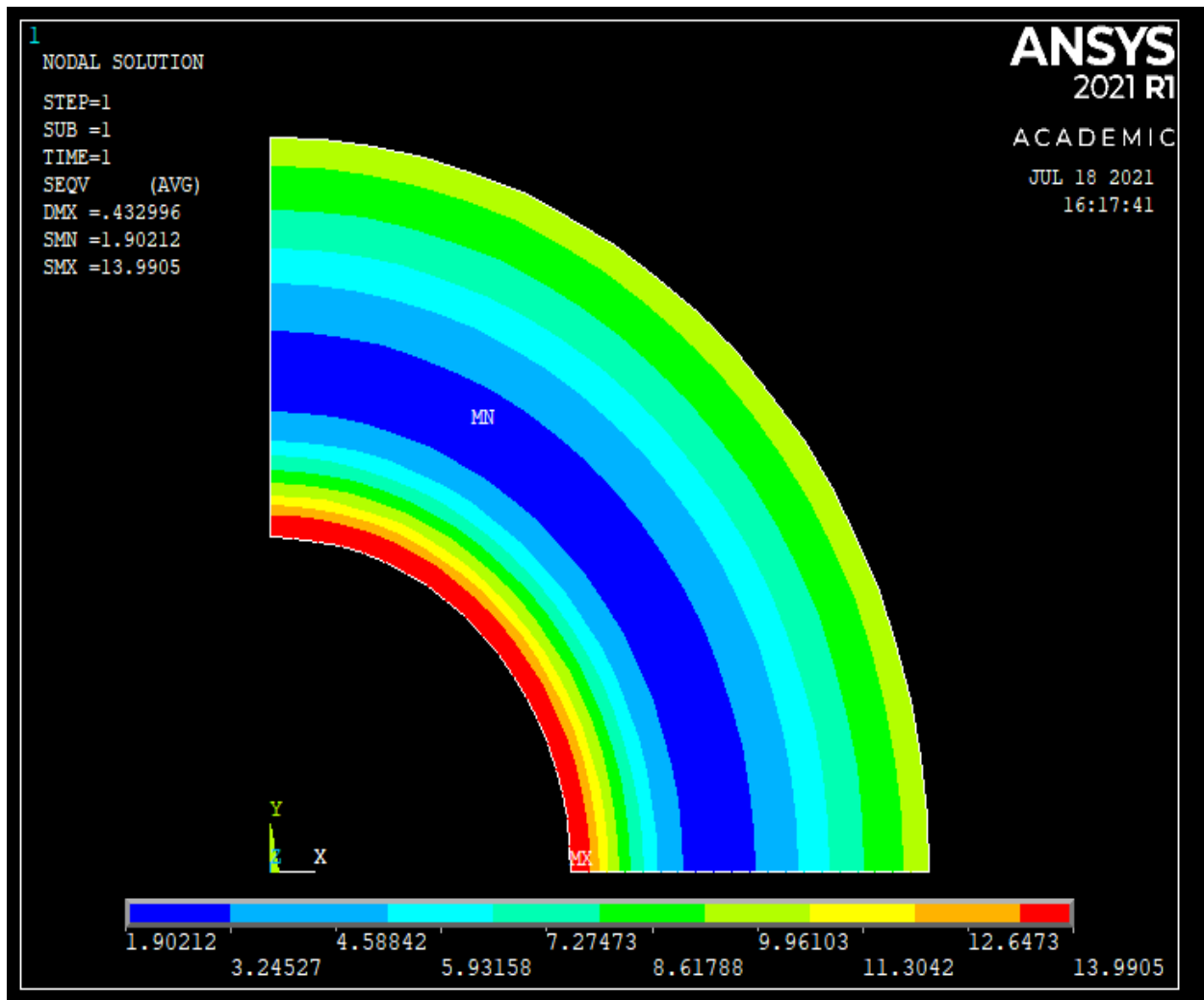

Figure 9. The stresses obtained from the ANSYS program for Disc-I.

Figure 10shows the stresses obtained from the ANSYS program for Disc-II.

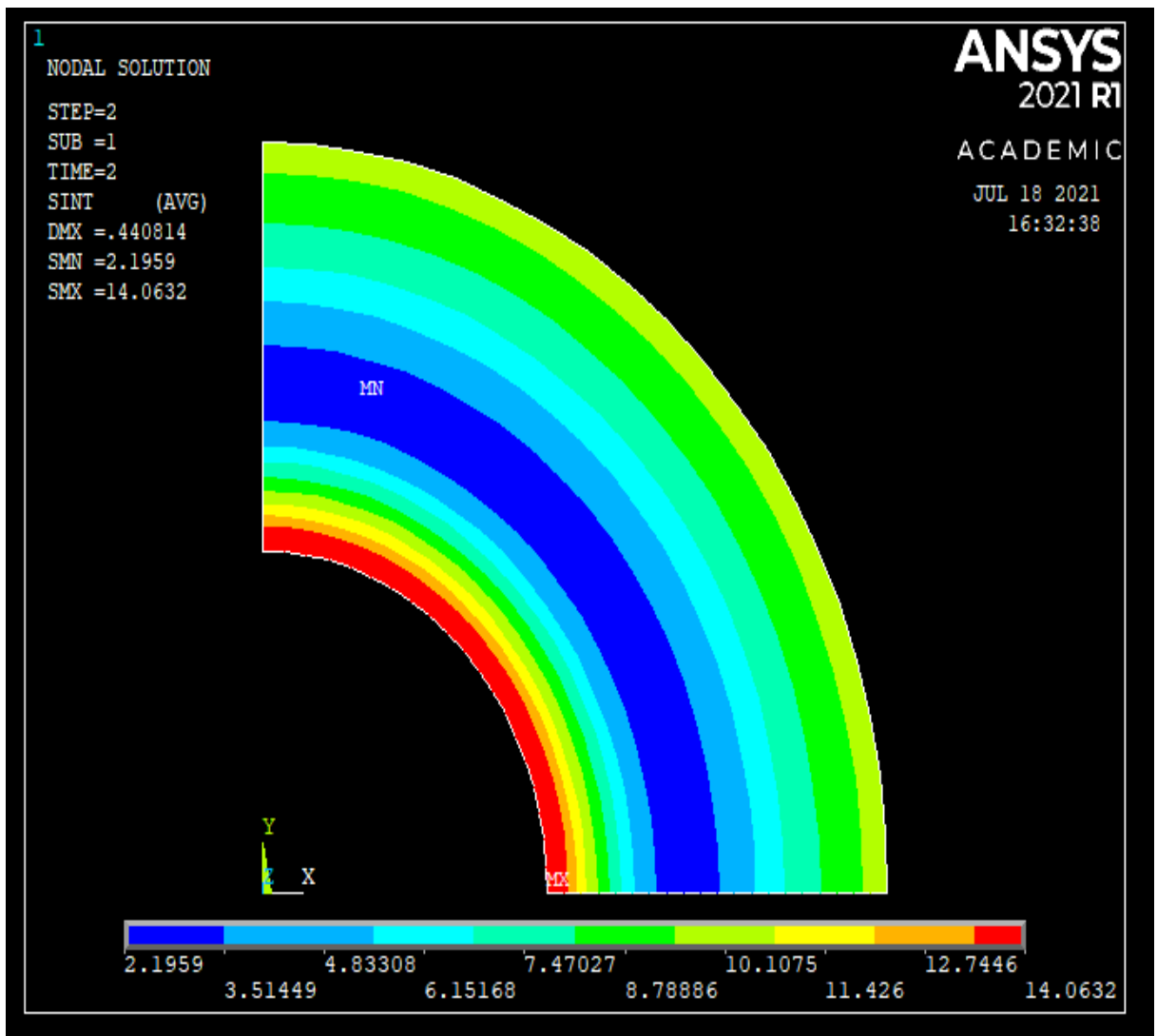

Figure 10. The stresses obtained from the ANSYS program for Disc-II. 
The results obtained in this study were compared with similar studies. For example, they stated that the tangential stresses occurring in the thermoplastic composite disk are greater than the stresses occurring in the radial direction [5]. Similarly, in this study; the calculated tangential stresses of it has been determined that there are more radial stresses. In both studies, the elastic stresses occurring in the innermost and outermost regions of the disks are zero.

\section{CONCLUSION}

Result In this study, elastic stresses occurring in disks consisting of two different materials were investigated. Disk materials are thermoplastic composite materials. The temperature varies parabolic from the inner region of the discs to the outer region. The finite element method of the ANSYS program was used for the solution. The result of the obtained solutions is summarized below. Due to the increase in temperatures, there are increases in stress values. The stresses determined at a temperature of $120^{\circ} \mathrm{C}$ are less than the stresses determined at a temperature of $30{ }^{\circ} \mathrm{C}$. For this reason, stresses are greater at high temperatures. Elastic stresses are directly related to temperature rise. Elastic deformation begins primarily on the inner surface of the disk. Considering the modules of elasticity of disks, the elastic stresses calculated in Disk-II with a high modulus of elasticity are greater than the elastic stresses occurring in Disk-I. The reinforcement ratio of steel wires directly affects the stresses.

For example, It has been determined that the stresses caused by Disc-II with a high steel wire reinforcement ratio are greater than Disc-I. It turns out that steel wire reinforcement can increase the strength of the material. Radial and tangential stresses from the inner surfaces of disks to the outer surfaces of disks $30^{\circ} \mathrm{C}-60^{\circ} \mathrm{C}-90^{\circ} \mathrm{C}-120^{\circ} \mathrm{C}$ for temperature values; radial stress components are always zero in the innermost region and outermost regions of disks. It is observed that the stress values increase with increasing temperature. The radial stresses calculated on the disks were determined as the tensile stress.

The tangential stresses that make up the disks are the tensile stress of the disks from the inner region to the middle region. It is determined as a pressing stress from the middle region of the disk to its outer part. Disc-II has high elasticity modules compared to Disc-I. The radial and tangential stresses occurring in Disc-II are greater than the radial and tangential stresses occurring in Disc-I. With this study, it is thought that thermoplastic composite materials, which are the reason of choice in spacecraft and airplanes, should be at optimum temperatures. It is assumed that the modulus of elasticity plays an important role in determining the resistance of materials to temperatures. At high temperatures, it is thought that it may be more advantageous to choose a material with a mechanical property when choosing any material.

\section{REFERENCES}

1. Doğan, A., Arıkan, V., "Low-velocity impact response of e-glass reinforced thermoset and thermoplastic based sandwich composites", Materials Science Composites Part B-engineering, Vol. 127, Issue 1, Pages 63$69,2017$.

2. Kayıran, H.F., "Investigation of thermal stress behavior of discs with different diameters of aluminum (Al2024- T3) boron carbide (B C)", 4th International Mediterranean Symposium, Pages 81-98, Mersin, 2020.

3. Kayıran, H.F., "Thermal stress analysis in a bimaterial disc”, Master Thesis, Süleyman Demirel University Institute of Science, Mechanical Engineering Department, Isparta, 2012.

4. Durodola, J., Attia, O., "Deformation and stresses in functionally graded rotating discs", Composites Science and Technology, Vol. 60, Issue 1, Pages 987-995, 2000.

5. Şen, F., Pekbey, Y., Sayman ,O., "Elastic-plastic stress analysis of a thermoplastic composite disc under parabolic temperature distribution", Indian Journal of Engineering and Materials Sciences, Vol. 14, Issue 1, Pages 282-288, 2007. 
6. Akay, M., Özden, S., "Measurement of residual stresses in injection molded thermoplastics”, Polymer Testing, Vol. 13, Issue 1, Pages 323-354, 1994.

7. Örçen, G., Gür, M., Solmaz, M.Y., "Plastic stress analysis in elliptical perforated thermoplastic layered composite plates", Journal of the Faculty of Engineering and Architecture of Gazi University, Vol. 24, Issue 4, Pages 667-674, 2009.

8. Kısmet, Y., Doğan A., "Characterization of the mechanical and thermal properties of rape short natural-fiber reinforced thermoplastic composites”, Iranian Polymer Journal, Vol. 5, Issue 1, Pages 1-9, 2021.

9. Karakuzu, R., Djele, A., Doğan, A., "High temperature effect on quasi-static and low velocity impact behaviors of advanced composite materials, proceedings of the institution of mechanical engineers, part c: journal of mechanical engineering science”, Vol. 235, Issue 23, Pages 7110-7119, 2021.

10. Doğan, A., Arman, Y., "The effect of hygrothermal aging on the glass and carbon reinforced epoxy composites for different stacking sequences”, Mechanics Of Solid Bodies, Vol. 24, Issue 1, Pages 19-25, 2018.

11. Evlen, H., Erel, G., "Effect of the reinforcement phase on the mechanical and biocompatibility properties of pla matrix nano composites", Vol. 45, Issue 4, Pages 491, 500, 2021.

12. Evlen, H., Akçaer, E., "Effects of carbon nanotube ratio on mechanical and morphological properties of a356carbon nanotube composites”, Acta Physica Polonica , Vol. 135, Issue 1, Pages 668-671, 2009.

13. Kayıran, H.F., "Numerical analysis of displacement of circular discs based on boron carbide $\left(\mathrm{B}^{4} \mathrm{C}\right)$-silicon carbide (sic) and silicon nitride $\left(\mathrm{Si}^{3} \mathrm{~N}^{4}\right)$ materials", El-Cezeri, Vol. 8, Issue 3, Pages 1108-1122, 2021.

14. Kayıran, H.F., "Examination of thermal stresses occurring in circular discs by finite element method", International Journal of 3D Printing Technologies and Digital Industry, Vol. 5, Issue 2, Pages 259-270, 2021.

15. Kayıran, H.F., "Numerical analysis of composite disks based on carbon/aramid-epoxy materials", Emerging Materials Research, Vol. 11, Issue 1, Pages 1-5, 2021.

16. Kayıran, H.F., "Numerical analysis of displacements in circular discs applied with different materials", Asia Mathematika, Vol. 5, Issue 1, Pages 168-177, 2021.

17. Çelen, Y.Y., Akkurt, İ., Kayıran, H.F., "Gamma ray shielding parameters of barium tetra titanate (BaTi4O9) ceramic”, Journal of Materials Science: Materials in Electronics, Vol. 32, Issue 1, Pages 18351-18362, 2021.

18. Akkurt, İ., Malidarre, R.B., Nafezi, G., Karpuz, N., Imamoglu, M., Boussaa, S.A., Ucar, M., Kayıran, H.F., "Photon attenuation coefficients and exposure buildup factor for hap-fe2o3 composite materials", Vol. 1, Issue 1, Pages 1-14, 2021.

19. Şenel, M., "Thermal elastic-plastic stress analysis of antisymmetric aluminum metal-matrix composite laminated plates under constant temperature change through the thickness", Journal of Reinforced Plastics and Composites, Vol. 22, Issue 1, Pages 897-912, 2003.

20. Bayat, M., Saleem, M., Sahari, B., Hamouda, A., Mahdi, E., “Analysis of functionally graded rotating discs with variable thickness”, Mechanics Research Communications, Vol. 35, Issue 1, Pages 283-309, 2008.

21. Sayyad, A.S., Ghugal, Y.M., Shinde, B.M., "Thermal stress analysis of laminated composite plates using exponential shear deformation theory", International Journal Automotive Composites, Vol. 2, Issue 1, Pages 23-39, 2016.

22. Timoshenko, S., Goodier, J.N., “Theory of elasticity”, McGraw-Hill, New York, Pages 77-90, 1970.

23. Kayıran, H.F., "Investigation of elastic tensile behavior of thermoplastic discs reinforced with steel wires", Journal of Intelligent Systems and Applications, Vol. 3, Issue 2, Pages 73-76, 2020. 
24. Şen, F., Palancıoğlu, H., "Thermal stress analysis in cross reinforced square perforated thermoplastic composite plates", Pamukkale University Journal of Engineering Sciences, Vol. 12, Issue 2, Pages 173-181, 2006.

25. Şen, F., "An investigation of thermal elastoplastic stress analysis of laminated thermoplastic composites with a circular hole under uniform temperature loading", Science and Engineering of Composite Materials, Vol. 13, Issue 1, Pages 213-224, 2006. 